\title{
Evaluation of leonardite as a feed additive on lipid metabolism and growth of weaned piglets
}

\author{
Matteo Dell'Anno ${ }^{a}$, Monika Hejna ${ }^{a}$, Stefania Sotira ${ }^{\mathrm{a}, *}$, Valentina Caprarulo ${ }^{\mathrm{a}}$, \\ Serena Reggi ${ }^{\mathrm{a}}$, Roberto Pilu ${ }^{\mathrm{b}}$, Francesco Miragoli ${ }^{\mathrm{c}}$, Maria Luisa Callegari ${ }^{\mathrm{c}}$, \\ Sara Panseri ${ }^{\mathrm{a}}$, Luciana Rossi ${ }^{\mathrm{a}}$ \\ ${ }^{a}$ Department of Health, Animal Science and Food Safety, Università Degli Studi Di Milano, Via Dell'Università 6, Lodi 26900, Italy \\ b Department of Agricultural and Environmental Sciences - Production, Land, Agroenergy, Università Degli Studi Di Milano, Via Celoria 2, Milan \\ 20133, Italy \\ ${ }^{\mathrm{c}}$ Department for Sustainable Food Process, Faculty of Agriculture, Food and Environmental Sciences, Università Cattolica Del Sacro Cuore, Via Emilia \\ Parmense 84, Piacenza 29122, Italy
}

\section{A R T I C L E I N F O}

\section{Keywords:}

Functional feed

Humic acids

Leonardite

Weaned piglets

Antioxidants

Feed additives

\begin{abstract}
A B S T R A C T
We evaluated the effects of leonardite supplementation, mainly composed of humic acids (HAs), as a functional feed additive in weaned piglets. One hundred and twenty piglets (Large Withe $x$ Landrace) were weaned at $28 \pm 2$ days, and randomly divided into two groups ( 6 pens per group, 10 piglets per pen). After one week of adaptation, for 40 days groups were fed a control diet (CTRL) and an HA enriched diet ( $0.25 \%$ of leonardite; HAG). Body weight (BW), average daily feed intake (ADFI), average daily gain (ADG), feed conversion ratio (FCR) were measured throughout the experimental period. On the last day of the trial four piglets per pen were randomly selected and the blood was collected to evaluate the serum metabolic profile and diamine oxidase content.

Chemical analyses showed that leonardite was characterized by a high content of ash $23.27 \%$ (as-fed basis), polyphenolic content of $35.18 \pm 3.91 \mathrm{mg} \mathrm{TAEq} / \mathrm{g}$, and an antioxidant capacity of $73.31 \pm 8.22 \mu \mathrm{mol}$ TroloxEq/g.

The HAG group showed an increase in BW, ADG and ADFI $(P<0.01)$ compared to the CTRL group during the experimental period. In terms of the serum metabolic profile, the HAG group showed a significant increase in total protein content $(P<0.001)$, albumin $(P<0.001)$, albumin/globulin ratio $(P<0.01)$, phosphatase alkaline $(P<0.01)$, calcium, phosphorus and magnesium $(P<0.05)$ compared to the CTRL group.

A modulation in the serum lipid profile was recorded. The HAG group showed a decrease in total triglycerides $(P<0.05)$ with higher total cholesterol $(P<0.05)$, however only high-density lipoprotein showed a significant increase $(P<0.001)$ compared to the CTRL group. No significant differences in the amount of diamine oxidase were found between groups.

In conclusion, leonardite inclusion in the diet at $0.25 \%$ was shown to have a positive effect on the serum lipid profile and animal growth. This thus suggests that leonardite can be considered as a new feed additive, which improves the health and performance of weaned piglets.
\end{abstract}

\footnotetext{
* Corresponding author.

E-mail address: stefania.sotira@unimi.it (S. Sotira).
} 


\section{Introduction}

Weaning is recognized a stressful period in intensively reared pigs, with a high occurrence of multifactorial diseases which are the most common reason for the use of antibiotics (Zhao et al., 2007). Managing weaning correctly is crucial, as it influences the use of antibiotics as well as long-term profitability. The European Food Safety Authority (EFSA) recommends adopting an integrated strategy in food-producing animals, reducing and also replacing the antibiotics with novel functional feed and additives (Cormican et al., 2017). Functional feed additives thus play a pivotal role, particularly concerning gastrointestinal disorders (Rossi et al., 2012; Heo et al., 2013).

Among many alternatives, leonardite which is used in veterinary practice for treating diarrhoea in horses, ruminants and poultry, has been proposed for preventing diarrhoea in animals (Ozturk et al., 2012; Domínguez-Negrete et al., 2019).

Leonardite is a microbial-derived product mainly composed of humic acids (HAs), which are derived from the decomposition of organic matter, usually exploited for the fertilization of soil. HAs also protect the mucosa of the intestine, with recognized antiinflammatory, antiphlogistic, adsorptive and antitoxic proprieties (Islam et al., 2005; Aksu and Bozkurt, 2009).

Natural humic substances may provide benefits to piglets' health during post-weaning (Trckova et al., 2017). They have shown antioxidant proprieties that could sustain the animals during the stressful period of weaning. They have also shown antimicrobial activity against pathogens leading to a decreased incidence of diarrhoea and better growth performance also modulating the animal's metabolism (Wang et al., 2008; Aeschbacher et al., 2012).

Humic acids and their sodium salts are permitted for oral use (inclusion level: $500-2000 \mathrm{mg} / \mathrm{kg}$ of body weight) in horses, ruminants, swine and poultry for the treatment of diarrhoea, dyspepsia and acute intoxications (EGTOP/1/, 2011). Lower levels of humic substances used as a feed additive $(2-10 \mathrm{~g} / 100 \mathrm{~g}$ of diet) in the pigs' diet seem to demonstrate that they improve growth performance and meat quality, also reducing ammonia emissions from manure (Ji et al., 2006; Wang et al., 2008; Kim et al., 2019).

Although encouraging findings concerning the use of HAs as a prophylactic tool for intestinal health have been reported, the inclusion of leonardite as a feed additive to promote growth, has not been extensively investigated. Several studies have revealed discordant findings in vivo probably due to the wide range of doses tested and the wide variability in the composition of humic-based products (Trckova et al., 2015; Kaevska et al., 2016; Trckova et al., 2018).

We focused on the inclusion of leonardite as a feed additive aimed at not substantially modifying the nutrient balance in the diet in order to simply be able to exploit the functional proprieties of leonartide. The aim of this study was thus to evaluate the effect of leonardite included at $0.25 \%$, as a natural material rich in HAs, on the principal metabolic parameters and growth of weaned piglets.

Leonardite was also assessed in terms of its chemical composition, phenolic content, and antioxidant capacity.

\section{Materials and methods}

\subsection{Chemical evaluation of experimental diets and leonardite}

The experimental diets and leonardite (Commission Regulation EU, 2017/, 1017), registration number 13.10.2; purchased from New Feed Team S.R.L. (Lodi, Italy) were characterized in terms of their principal constituents: humidity, ether extract (EE), crude protein (CP), crude fiber (CF), and ash contents. The samples were analyzed in duplicate following official analysis methods (AOAC, 2005). Dry matter (DM) was obtained by inserting samples into previously weighed aluminum bags, which were dried in a forced-air oven at $105{ }^{\circ} \mathrm{C}$ for $24 \mathrm{~h}$ (AOAC method 930.15).

Ash was obtained using a muffle furnace at $550{ }^{\circ} \mathrm{C}$ (AOAC method 942.05). CP was determined by a Kjeldahl method (AOAC method 2001.11). EE was determined using ether extraction in the Soxtec system (DM 21/12/1998). CF was determined by the filtering bag technique (AOCS method Ba 6a-05).

The mineral composition of the two experimental diets and leonardite were evaluated after mineralization with inductively coupled plasma mass spectrometry (ICP-MS). First, calibration curves for each element considered (Na, Mg, Al, K, Ca, Cr, Mn, Fe, Co, $\mathrm{Ni}, \mathrm{Cu}, \mathrm{Zn}, \mathrm{As}, \mathrm{Se}, \mathrm{Mo}, \mathrm{Cd}, \mathrm{Pb}, \mathrm{P})$ were obtained using certified reference materials. Dried samples (0.3 g) were digested by a microwave digestion system (Anton Paar MULTIWAVE-ECO) in Teflon tubes filled with $10 \mathrm{~mL}$ of $65 \% \mathrm{HNO}_{3}$ by applying a one-step temperature ramp (at $120{ }^{\circ} \mathrm{C}$ in $10 \mathrm{~min}$ and maintained for $10 \mathrm{~min}$ ).

The mineralized samples were cooled for $20 \mathrm{~min}$ and then transferred into the polypropylene test tubes. Mineralized samples were diluted 1:100 with $0.3 \mathrm{M} \mathrm{HNO}_{3}$ in MilliQ Water. The concentration of elements was measured by ICP-MS (BRUKER Aurora-M90 ICPMS). In order to check the nebulization performance, an aliquot of a $2 \mathrm{mg} / \mathrm{L}$ of an internal standard solution $\left({ }^{72} \mathrm{Ge},{ }^{89} \mathrm{Y}\right.$, $\left.{ }^{159} \mathrm{~Tb}\right){ }^{\text {was }}$ added to the samples to produce a final concentration of $20 \mu \mathrm{g} / \mathrm{L}$. Polyatomic interference was removed using a collision-reaction interface (CRI) with an $\mathrm{H}_{2}$ flow of $80 \mathrm{~mL} / \mathrm{min}$ through skimmer cone.

The fatty acid profile of the experimental diets was analyzed starting with the total lipid extraction and preparation of the fatty acid methyl esters (Christie and Han, 2003). The fatty acid analysis was carried out using gas chromatography (TRACE GC Ultra, Thermo Fisher Scientific, Rodano, Italy) fitted with an automatic sampler (AI 1300, Thermo Fisher Scientific) and flame ionization detector (FID). An RT-2560 fused silica capillary column (100 m $\times 0.25 \mathrm{~mm} \times 0.25 \mu \mathrm{m}$ film thickness; Restek, Milan, Italy) was used with a programmed temperature from $80^{\circ} \mathrm{C}$ to $180{ }^{\circ} \mathrm{C}$ at $3{ }^{\circ} \mathrm{C} / \mathrm{min}$, then from $180{ }^{\circ} \mathrm{C}$ to $250{ }^{\circ} \mathrm{C}$ at $2.5^{\circ} \mathrm{C} / \mathrm{min}$, which was then held for $10 \mathrm{~min}$. The carrier gas was helium at $1.0 \mathrm{~mL} / \mathrm{min}$ with an inlet pressure of $16.9 \mathrm{psi}$. A quantitative procedure was used where $1 \mathrm{~mL}$ of internal standard (1 mg/mL 23:0 methyl ester; N-23-M; Nu-Chek Prep Inc., Elysian, MN, USA) was added prior to methylation. The fatty acid methyl ester (FAME) contents were quantified by weight as a percentage of the total FAMEs. All analyses were performed in duplicate. 


\subsection{Polyphenolic content of leonardite}

The phenolic content of leonardite was evaluated by the Folin-Ciocalteu method following Attard (2013). Polyphenolic extract was obtained by diluting $2.5 \mathrm{~g}$ of sample with $15 \mathrm{~mL}$ of methanol (100\%), which was then allowed to macerate for $24 \mathrm{~h}$ at room temperature. The samples were centrifugated $(3000 \mathrm{rpm}, 10 \mathrm{~min})$ and the supernatants were collected and stored at $-20{ }^{\circ} \mathrm{C}$ for further polyphenol evaluation. The assay was performed by reacting $50 \mu \mathrm{L}$ of extracted sample/standard with $500 \mu \mathrm{L}$ of FolinCiocalteu reagent $(10 \%$ in water) and $400 \mu \mathrm{L}$ sodium carbonate $(1 \mathrm{M})$. The reaction mixture was left to stand for 15 min in the dark and the total phenolic content was determined spectrophotometrically at $630 \mathrm{~nm}$ (JASCO V-630 UV-vis, Germany). Calibration curves were prepared with tannic acid from $480 \mu \mathrm{g} / \mathrm{mL}$ to $15 \mu \mathrm{g} / \mathrm{mL}$ as standard. The results were expressed as mg/100 $\mathrm{g}$ of tannic acid equivalent (mg TAEq/100 g).

\subsection{Trolox equivalent antioxidant capacity assay (TEAC)}

Leonardite was evaluated for its antioxidant proprieties using an ABTS radical cation discoloration assay (Prior et al., 2005). First the dried samples were diluted in water $(100 \mathrm{mg} / \mathrm{mL})$ and adjusted from an initial $\mathrm{pH}$ of 3.5 to $\mathrm{pH} 9 \mathrm{by}$ adding $\mathrm{NaOH}(1 \mathrm{M})$ thus facilitating the solubilization of humic acids. The sample was then stirred for $24 \mathrm{~h}$ at room temperature. The solution was centrifuged for $10 \mathrm{~min}$ at $3000 \mathrm{rpm}$, the supernatant was collected and stored at $-20{ }^{\circ} \mathrm{C}$ until the analysis. Before proceeding with the assay, the humic acid extract was adjusted to $\mathrm{pH} 7$ with $\mathrm{HCl}(1 \mathrm{M})$, filtered with an $0.45 \mu \mathrm{m}$ syringe filter, and diluted in order to obtain a clear solution that would not alter the reading of the spectrophotometer. In order to assess a possible dose related antioxidant effect, the concentrations tested were: 5\%,2\%, 1.25\% of the humic acid original extract (Dell'Anno et al., 2020). The antioxidant activity was tested by adopting the ABTS assay, according to Prior et al. (2005).

The reaction mixture with 2,2'-azino-bis (3-ethylbenzothiazoline-6-sulfonic acid) $\left(\mathrm{ABTS}^{{ }^{+}}\right.$) was generated by the reaction of 7 mM ABTS with $2.45 \mathrm{mM}$ of K-persulfate. The reaction mixture was left to stand in the dark for $16 \mathrm{~h}$ at room temperature and used within two days. The working solution of the $\mathrm{ABTS}^{*+}$ radical cation was obtained by diluting $\mathrm{ABTS}^{*+}$ in ethanol in order to obtain an absorbance of $0.700 \pm 0.02 \mathrm{OD}$ at $734 \mathrm{~nm}$ at room temperature. First, a calibration curve was obtained using different concentrations (2000 $\mu \mathrm{M}, 1500 \mu \mathrm{M}, 1000 \mu \mathrm{M}, 500 \mu \mathrm{M}, 100 \mu \mathrm{M}, 0 \mu \mathrm{M})$ of Trolox (6-hydroxy-2,5,7,8-tetramethychroman-2-carboxylic acid) as standard. The assay was performed using $10 \mu \mathrm{L}$ of diluted sample (standard and extract) added to 1 mL of working solution (ABTs ${ }^{*+}$ ). The absorbances were recorded spectrophotometrically (JASCO V-630 UV-vis, Germany) at $734 \mathrm{~nm}$ from 1 to $6 \mathrm{~min}$.

The total antioxidant capacity was expressed as the percentage inhibition (PI), according to the equation: $\mathrm{PI}=\left[\left(\mathrm{AbsABTS}{ }^{+}-\mathrm{Abs}^{\circ}\right.\right.$ sample) $\left./ \mathrm{AbsABTS}^{*+}\right] \times 100$, where AbsABTS ${ }^{*+}$ denotes the initial absorbance of diluted ABTS ${ }^{*+}$, and the Abs sample denotes the absorbance of the sample at every $6 \mathrm{~min}$ of reaction. Using appropriate calibration curves, the result was expressed as the equivalent concentration of $\mu \mathrm{mol}$ Trolox/g after $6 \mathrm{~min}$ of reaction ( $\mu \mathrm{mol}$ TroloxEq/g).

\subsection{Experimental design and sample collection}

The experimental trial was approved by the Animal Welfare Body of the University of Milan (protocol No. 31/2019) and performed in accordance with European regulations (Commission Directive, 2010/6/EU). It was conducted on a commercial farm that was free from pathologies included in the ex-list A of the World Organization for Animal Health (Porcine Reproductive Respiratory Syndrome, atrophic rhinitis, transmissible gastroenteritis, salmonellosis, Aujeszky disease).

A total of 120 crossbred piglets (Large White $\times$ Landrace), weaned at $28 \pm 2$ days (50\% female and $50 \%$ male), were housed in 12 different pens, in homogeneous environmental conditions $\left(27{ }^{\circ} \mathrm{C}\right.$ and $60 \%$ relative humidity). In order to guarantee a homogeneous weight intra-pen and inter-group, the piglets (10 animals/pen) were randomly assigned to the control group (CTRL: 6 pens, 60 piglets) and treatment with an HA enriched diet (0.25\% of leonardite; HAG: 6 pens, 60 piglets).

The two experimental isoproteic and isoenergetic diets (Table 1) were formulated using Plurimix software (Fabermatica, Cremona, Italy) in order to meet the nutritional requirements for post-weaned piglets (NRC, 2012) and were provided by Ferraroni S.p.a. (Cremona, Italy). Both experimental diets were formulated including 1\% coconut oil (Table 1), a raw ingredient characterized by high digestibility, as an enhancer of palatability for young animals, taking into account the balance in the saturated and unsaturated fatty acid ratio.

After an adaptation period of seven days with the same basal diet, piglets were fed the experimental diets (CTRL and HAG) ad libitum from day 0 to day 40 .

Body weight (BW) was individually recorded using a validated scale at the beginning (d 0), day 14 (d 14), day 28 (d 28) and day 40 (d 40). Feed intake was recorded weekly for each pen by measuring the feed refuse per pen. Based on the BW results, the average daily gain (ADG), average daily feed intake (ADFI) and feed conversion ratio (FCR) were calculated. In terms of zootechnical performance, each pen was considered as the experimental unit. At day 40, four animals from each pen were randomly selected, in order to collect faeces from the rectal ampulla of four animals per pen (total samples CTRL: $\mathrm{n}=24$; total samples: HAG $\mathrm{n}=24$ ), and blood samples from the jugular vein of four animals per pen (total samples CTRL: $n=24$; total samples: HAG $n=24$ ) using vacuum tubes. The health status was evaluated daily and individual fecal consistency was scored weekly using a four-level scale: $0=$ normal (faeces firm and well formed), 1 = soft consistency (faeces soft and formed), 2 = mild diarrhoea (loose faeces, usually yellowish), $3=$ severe diarrhoea (faeces watery and projectile). A fecal consistency score $\leq 1(0,1)$ was considered normal, whereas a fecal score $>1(2,3)$ was defined as indicative of diarrhoea (Rossi et al., 2014). 
Table 1

Diet composition of in vivo trial (\% as fed basis) divided by control (CTRL) and treatment group fed with HA enriched diet $(0.25 \%$ leonardite).

\begin{tabular}{|c|c|c|}
\hline Items & CTRL & HAG \\
\hline \multicolumn{3}{|l|}{ Ingredients, $\%$ as fed basis } \\
\hline Barley, meal & 25.15 & 25.15 \\
\hline Wheat, meal & 19.41 & 19.36 \\
\hline Corn, flakes & 14.03 & 13.83 \\
\hline Corn, meal & 4.85 & 4.85 \\
\hline Soybean, meal & 4.65 & 4.65 \\
\hline Soy protein concentrates & 4.11 & 4.11 \\
\hline Biscuits, meal & 4.00 & 4.00 \\
\hline Dextrose monohydrate & 3.50 & 3.50 \\
\hline Wheat middling & 4.32 & 4.32 \\
\hline Whey protein concentrate & 3.00 & 3.00 \\
\hline Fish, meal & 2.50 & 2.50 \\
\hline Milk whey & 2.50 & 2.50 \\
\hline Coconut oil & 1.00 & 1.00 \\
\hline Soy oil & 1.00 & 1.00 \\
\hline Plasma, meal & 1.00 & 1.00 \\
\hline Organic Acids ${ }^{1}$ & 1.00 & 1.00 \\
\hline Dicalcium phosphate & 0.85 & 0.85 \\
\hline Animal fats & 0.70 & 0.70 \\
\hline L-Lysine & 0.50 & 0.50 \\
\hline Benzoic acid & 0.40 & 0.40 \\
\hline L-Threonine & 0.35 & 0.35 \\
\hline DL-Methionine & 0.35 & 0.35 \\
\hline Sodium Chloride & 0.27 & 0.27 \\
\hline Vitamins $^{2}$ & 0.25 & 0.25 \\
\hline L-Valine $(96.5 \%)$ & 0.15 & 0.15 \\
\hline L-Tryptophan & 0.08 & 0.08 \\
\hline Flavoring $^{3}$ & 0.04 & 0.04 \\
\hline Copper sulfate & 0.04 & 0.04 \\
\hline Leonardite & - & 0.25 \\
\hline \multicolumn{3}{|c|}{ Calculated nutrient levels ${ }^{4}, \%$ as fed basis } \\
\hline Crude protein & 16.92 & 16.88 \\
\hline Ether extract & 5.06 & 5.19 \\
\hline Crude fiber & 3.15 & 3.22 \\
\hline Ashes & 5.1 & 5.1 \\
\hline $\mathrm{DE}^{5}(\mathrm{Mc} / \mathrm{Kg})$ & 3.43 & 3.43 \\
\hline
\end{tabular}

HA: humic acids; HAG: humic acid enriched diet group supplemented with $0.25 \%$ leonardite.

${ }^{1}$ Organic Acids: formic acid, sodium formate, sorbic acid, orthophosphoric acid, calcium formate, citric acid, and fumaric acid.

${ }^{2}$ Vitamins and vitamin-like compounds per kg: Vitamin A, 10,000; Vitamin D3, 1000 IU; Vitamin E, $100 \mathrm{mg}$; Vitamin B1, $3 \mathrm{mg}$; Vitamin B2, $96.3 \mathrm{mg}$; Vitamin B6, $5.8 \mathrm{mg}$; Calcium D-pantothenate, $27 \mathrm{mg}$; Vitamin B12, $0.040 \mathrm{mg}$; Vitamin K3, $4.8 \mathrm{mg}$; Biotin, $0.19 \mathrm{mg}$; Niacinamide, $35 \mathrm{mg}$; Folic Acid, $1.4 \mathrm{mg}$. Choline chloride $120 \mathrm{mg}$, Betaine chloride $70 \mathrm{mg}$.

${ }^{3}$ Vanilla flavoring.

${ }^{4}$ Calculation performed with Purimix software (Fabermatica, Cremona, Italy).

${ }^{5}$ DE: digestible energy content estimated from NRC (2012).

\subsection{Biological sample analysis}

Blood samples ( 4 animals/pen) were allowed to clot for $2 \mathrm{~h}$ at room temperature. Serum samples were obtained by centrifugation and were evaluated by a multiparametric autoanalyzer for clinical chemistry (ILab 650; Instrumentation Laboratory Company, Lexington, MA, USA) at $37{ }^{\circ} \mathrm{C}$ for the following metabolic parameters: total protein content, albumin, globulin, albumin/globulin (A/ G), urea, alanine aminotransferase (ALT-GPT), aspartate aminotransferase (AST-GOT), phosphatase alkaline (ALP), total bilirubin, glucose, total cholesterol, calcium (Ca), phosphorus (P), magnesium (Mg), total triglycerides, high-density lipoproteins (HDL), lowdensity lipoproteins (LDL), and creatinine.

Diamine oxidase concentrations in serum samples (dilution 1:10), as an indirect marker of intestinal integrity (Zhang et al., 2013), were evaluated using a DAO enzyme-linked immunosorbent assay (DAO; Wuhan Fine Biotech Co., Ltd., China). The following conditions were used: 96-well pre-coated microplates were washed twice, after which $100 \mu \mathrm{L}$ of standard or sample were added to each well and incubated at $37^{\circ} \mathrm{C}$ for $90 \mathrm{~min}$. The plates were washed and $100 \mu \mathrm{L}$ of diluted detection antibody were added to each well and incubated at $37{ }^{\circ} \mathrm{C}$ for $60 \mathrm{~min}$. After washing, $90 \mu \mathrm{L}$ of TMB substrate solution were added to each well. The plate was left in the dark at $37^{\circ} \mathrm{C}$ for $15 \mathrm{~min}$, then the reaction was stopped by adding $50 \mu \mathrm{L}$ of stop solution to each well. Absorbance was measured on a plate reader at $450 \mathrm{~nm}$ (Bio-Rad 680 Microplate Reader; Bio-Rad Laboratories, Inc., Hercules, California, USA). For each plate, a 
calibration curve was adopted to calculate the DAO concentration of each sample using Curve Expert v. 1.4 software. The concentrations determined were expressed as nanograms of DAO per $\mathrm{mL}(\mathrm{ng} / \mathrm{mL}$ ).

Collected fecal samples were analyzed by RT-PCR to estimate the bacterial DNA abundance of the main enteric microorganisms as the parameter of gut health. Bacterial DNA was extracted as reported by Patrone et al. (2018). Copy numbers of the 16S rRNA gene from Escherichia coli, Enterobacteriaceae, Bifidobacterium spp. and Lactobacillus spp. were quantified using previously reported primers (Penders et al., 2005; Bartosch et al., 2004; Byun et al., 2004). Quantification was carried out in triplicate using the LightCycler 480 Instrument II (Roche Diagnostics, Monza, Italy). Bifidobacterium spp., Lactobacillus spp. and Enterobacteriaceae were quantified using the KAPA SYBRR FAST (Kapa Biosystems, Inc; Wilmington, MA) containing a $300 \mathrm{nM}$ final primer concentration. On the other hand, E. coli was quantified using the KAPA Probe FAST Master mix (Kapa Biosystems, Inc; Wilmington, MA) containing $500 \mathrm{nM}$ of primers and $100 \mathrm{nM}$ of the probe (final concentration). The primers and probes used for the quantification of $E$. coli were described by Penders et al. (2005). Bifidobacterium infantis ATCC 15697D and E. coli ATCC 700926D-5 genomic DNAs, used for preparing standard curves, were provided by the American Type Culture Collection (ATCC). Genomic DNA of Lactobacillus fermentum DSM20052 was obtained by extracting $5 \mathrm{~mL}$ of activated culture using the Genomic DNA extraction Kit (Promega) and quantified with a Qubit ${ }^{\mathrm{TM}}$ fluorometer (Invitrogen, Milan, Italy). Standard curves were obtained by 10-fold dilutions of genomic DNA for each reference genomic DNA. Results were expressed as ng of target DNA/ng of total fecal bacterial DNA. The four samples analyzed for each pen were considered as replicates for each treatment.

\subsection{Statistical analysis}

Data on zootechnical performance, biological samples, antioxidant capacity and diamine oxidase were evaluated using SAS 9.4 (SAS Inst. Inc., Cary, NC). Before analyses, all data were tested for normality with the Shapiro-Wilk test (for values $>0.9$ data were considered normally distributed).

The data were analyzed with the general linear model. The model included the effect of treatments, and for the zootechnical performance, the effect of time (Day) and the interaction between treatment and time (TRT $\times$ Day) were included. Tukey-Kramer studentized adjustments were used to separate the means, and the results were reported as LSMEANS and SEM or standard error (SE). Means were considered different when $P \leq 0.05$ and tended to different if $0.05<P \leq 0.1$.

\section{Results and discussion}

\subsection{Chemical characterization of experimental diets and leonardite}

Leonardite is a heterogeneous mixture of polydisperse material formed by humification. The variability of the environment during humification significantly influences the final composition of leonardite. This is confirmed by the wide heterogeneity of commercial products for animal nutrition. The chemical characterization of leonardite enabled our results to be compared with other findings.

Our results revealed that the main component of leonardite was ash, corresponding to $23.27 \%$, confirming the high content of minerals although a wide range from 15 to $70 \%$ on dry basis is reported in the literature (Chammui et al., 2014). Our experimental diets showed a mineral content in line with regulations (Regulation EC, 1831/, 2003). Nevertheless, the high level of minerals did not notably alter the mineral levels as a result of the inclusion of $0.25 \%$ of leonardite in the diet, considering the maximum levels permitted by Reg. EC 1831/2011. This percentage inclusion also reduced the dustiness and obtained optimal mixing conditions during the feed production phases. The inclusion of leonardite did not affect the fatty acid profile of the diets (Table 2).

Leonardite showed a high content of $\mathrm{Ca}, \mathrm{Fe}$ and $\mathrm{Al}$. The contaminants ( $\mathrm{As}, \mathrm{Pb}, \mathrm{Cd}$ ) were scarce and below the safety limits (Commission Regulation EU, 1275/, 2013). Moreover, no contaminants (under the detection limits) were revealed in the diet supplemented with $0.25 \%$ leonardite.

In order to reduce the emission of heavy metals into the environment and optimize the diet for a better exploitation of macro and microelements, the level of minerals in feed ingredients should always be evaluated in order to guarantee the correct diet formulation (Hejna et al., 2019) (Table 3)

\subsection{Polyphenolic content of leonardite}

Results from the Folin-Ciocalteu method revealed that leonardite was characterized by $35.18 \pm 3.91 \mathrm{mg}$ TAEq/100 $\mathrm{g}$ of polyphenols. Polyphenols such as hydroxytyrosol from olive oil, isoflavones from soy proanthocyanidins in grape seed extracts (Mennen et al., 2005), were evaluated as indirect indicators of the antioxidant proprieties of humic substances. The recommended dose of polyphenol intake in the human diet is $396 \mathrm{mg} / \mathrm{d}$ (Ma and Chen, 2020). Polyphenols are commonly found in plants as secondary metabolites, which aid the plant in structural development and react to many biotic and abiotic stressors with well recognized antioxidant activities (Jessica et al., 2019). Our results confirmed that humic acids are a source of antioxidant compounds (Karadirek et al., 2016; Lv et al., 2018). Considering the variability in the phenolic content of microbial-originated products, our results enabled us to identify the properties leonardite.

Although the amount of polyphenols obtained was lower compared with other feed and food products (Castrica et al., 2019), the leonardite antioxidant capacity should be considered high because the phenolic content is comparable to round melon (Praecitrullus vulgaris). However its antioxidant capacity is higher than the $\mu \mathrm{mol}$ TroloxEq/g content of lemon and orange water-soluble extracts (Kaur and Kapoor, 2002; Nilsson et al., 2005) which are considered as beneficial foods with positive effects on health. Humic acids 
Table 2

Chemical composition of diets for control group (CTRL), treatment group (HAG) and leonardite (LEO). All values are expressed as percentage as fed-basis (\%).

\begin{tabular}{llll}
\hline & CTRL & HAG & LEO \\
\hline DM & 91.62 & 91.62 & 81.13 \\
CP & 16.24 & 16.57 & 6.15 \\
EE & 3.79 & 3.87 & 0.6 \\
CF & 2.69 & 2.24 & 5.15 \\
Ashes & 4.59 & 4.46 & 23.27 \\
\hline
\end{tabular}

FA composition (\% total FAMEs)

\begin{tabular}{|c|c|c|}
\hline & CTRL & HAG \\
\hline C 8:0 & 0.78 & 0.80 \\
\hline C $10: 0$ & 0.74 & 0.81 \\
\hline C $12: 0$ & 6.68 & 7.26 \\
\hline C $14: 0$ & 3.82 & 4.05 \\
\hline C $14: 1$ & 0.01 & 0.02 \\
\hline C $15: 0$ & 0.09 & 0.09 \\
\hline C $16: 0$ & 16.36 & 16.32 \\
\hline C $16: 1$ & 0.81 & 0.81 \\
\hline C $17: 0$ & 0.13 & 0.12 \\
\hline C $17: 1$ & 0.06 & 0.06 \\
\hline C 18:0 & 4.87 & 4.85 \\
\hline C $18: 1$ n9 trans & 0.06 & 0.06 \\
\hline C $18: 1 \mathrm{n} 9 \mathrm{cis}$ & 24.15 & 23.71 \\
\hline C $18: 2$ n6 cis & 35.49 & 35.18 \\
\hline C $20: 0$ & 0.29 & 0.28 \\
\hline C $18: 3$ n6 & 0.04 & 0.02 \\
\hline C $20: 1$ & 0.67 & 0.63 \\
\hline C $18: 3$ n 3 & 2.62 & 2.64 \\
\hline C $21: 0$ & 0.02 & 0.03 \\
\hline C $20: 2$ & 0.10 & 0.14 \\
\hline C 22:0 & 0.19 & 0.19 \\
\hline C $20: 3$ n6 & 0.01 & 0.01 \\
\hline C 22:1 n9 & 0.04 & 0.04 \\
\hline C $20: 3$ n 3 & 0.04 & 0.03 \\
\hline C $20: 4$ n6 & 0.11 & 0.09 \\
\hline C $22: 2$ & 0.02 & 0.02 \\
\hline C $24: 0$ & 0.15 & 0.14 \\
\hline C $20: 5$ n 3 & 0.64 & 0.65 \\
\hline C $24: 1$ & 0.05 & 0.04 \\
\hline C $22: 6$ n 3 & 0.90 & 0.92 \\
\hline
\end{tabular}

DM: dry matter; CP: crude protein; EE: ether extract; CF: crude fiber; FA: fatty acids; FAMEs: fatty acid methyl esters; CTRL: control group; HAG: humic acid enriched diet group supplemented with $0.25 \%$ of leonardite; LEO: leonardite, humic acid-based feed ingredient.

can thus be considered as promising biologically-active natural antioxidants for the development of new classes of pharmaceuticals for medicine (Khil'ko et al., 2011).

\subsection{Trolox equivalent antioxidant capacity (TEAC) of leonardite}

Our results showed that the humic acid extract contained a dose-dependent antioxidant capacity (Fig. $1 ; P<0.0001$ ), with a measured amount of 73.31 $\pm 8.22 \mu \mathrm{mol}$ TroloxEq/g after $6 \mathrm{~min}$. This is in line with other studies on the antioxidant activity of humic substances (Aeschbacher et al., 2012; Smirnova et al., 2012), thus suggesting that the effect is probably related to the content of phenolic moieties as the most important electron-donating groups. In addition, the presence of acid groups $(-\mathrm{COOH},-\mathrm{OH})$ suggests that these substances are capable of an antioxidant effect (Smirnova et al., 2012). The effectiveness of humic substances related to their dose-effect response has also been observed by the gas-volumetric method (Efimova et al., 2012). The results obtained from the latter study showed that leonardite has an antioxidant capacity, highlighting its possible positive effects on animal health by reducing oxidation.

\subsection{Zootechnical performance}

The final average body weight increased significantly in HAG piglets compared to the CTRL group confirming the positive effect of leonardite treatment on animal growth. The HAG group showed a higher average BW at d 40 compared to CTRL $(P<0.001)$. HAG 
Table 3

Results of mineral profile analyzed by ICP-MS of two experimental diets (CTRL and HAG diet supplemented with $0.25 \%$ leonardite) and leonardite (LEO, humic acids-based feed ingredient). All values are expressed as $\mathrm{ppm}$ as fed (mg/kg AF).

\begin{tabular}{llll}
\hline & CTRL & HAG & LEO \\
\hline $\mathrm{Na}$ & 1595.72 & 1697.16 & 1586.39 \\
$\mathrm{Mg}$ & 1532.20 & 1588.64 & 1524.63 \\
$\mathrm{Al}$ & 177.23 & 222.49 & 8763.21 \\
$\mathrm{~K}$ & 7621.32 & 8026.69 & 721.39 \\
$\mathrm{Ca}$ & 4868.93 & 4995.59 & 8309.21 \\
$\mathrm{Cr}$ & 2.57 & 2.78 & 7.69 \\
$\mathrm{Mn}$ & 68.92 & 76.08 & 133.33 \\
$\mathrm{Fe}$ & 262.84 & 316.43 & 6649.14 \\
$\mathrm{Co}$ & n.d. & n.d. & 3.50 \\
$\mathrm{Ni}$ & n.d. & n.d. & 6.33 \\
$\mathrm{Cu}$ & 116.39 & 98.72 & 4.52 \\
$\mathrm{Zn}$ & 133.08 & 146.15 & 10.75 \\
$\mathrm{As}$ & n.d. & n.d. & 4.28 \\
$\mathrm{Se}$ & 2.40 & 1.16 & 0.59 \\
$\mathrm{Mo}$ & 0.81 & 0.59 & n.d. \\
$\mathrm{Cd}$ & n.d. & n.d. & n.d. \\
$\mathrm{Pb}$ & n.d. & n.d. & 5.43 \\
$\mathrm{P}$ & 6082.46 & 6339.63 & n.d. \\
\hline
\end{tabular}

n.d. = not detectable.

AF: as fed; CTRL: control group; HAG: humic acid enriched diet group supplemented with $0.25 \%$ leonardite; LEO: leonardite, humic acid-based feed ingredient.

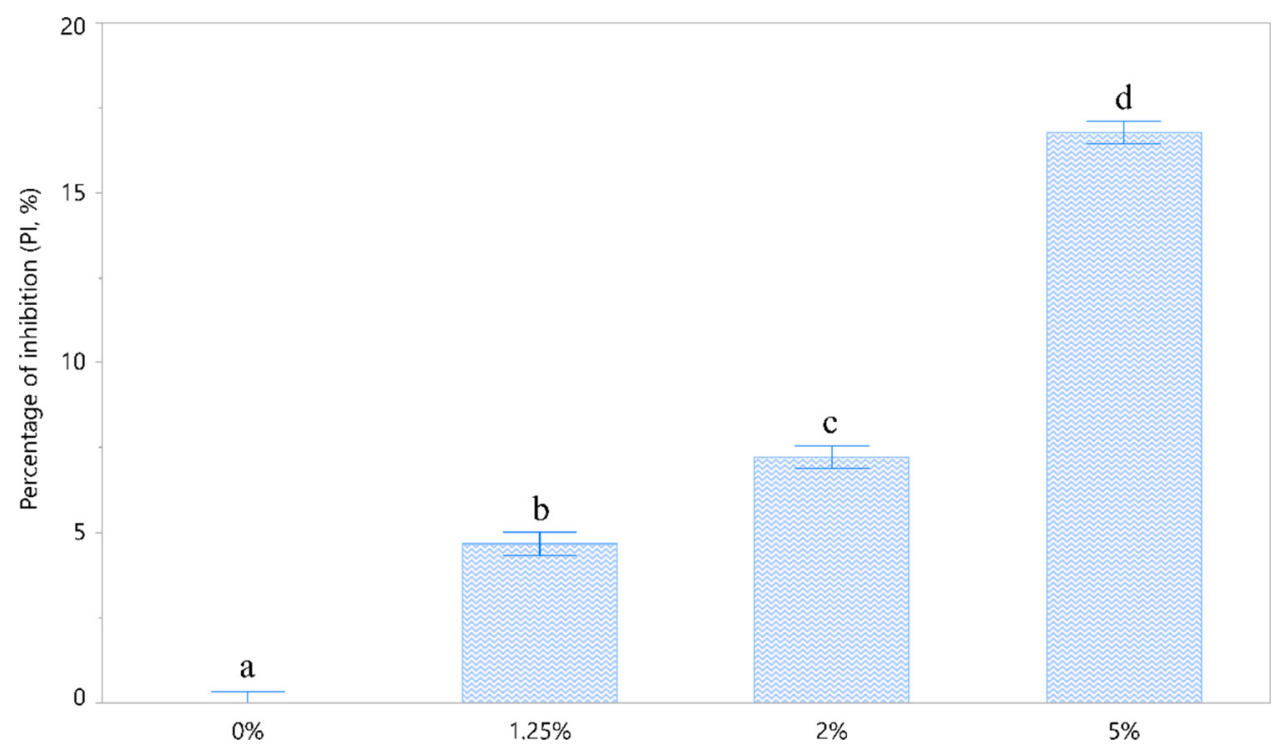

Fig. 1. Percentage inhibition of $\mathrm{ABTS}^{*+}$ of different concentrations of humic acids extract (blank: $0 \% ; 1.25 \%$; $2 \%$ and $5 \%$ ) measured by Trolox Equivalent Antioxidant Capacity (TEAC) assay.

a-b means with different superscripts are significantly different between treatments $(P<0.0001)$. Data are expressed as least square means (LSMEANS) and Standard Error (SE).

ABTS: 2,2'-azino-bis (3-ethylbenzothiazoline-6-sulfonic acid).

also showed a higher ADG from d 14 to 28 and from d 28 to $40(P<0.001$, Table 4). The ADFI of the HAG group increased from d 14 to 28 and d 28 to $40(P<0.01$; Table 4$)$ compared to the CTRL group. The higher final body weight of the HAG group was due to a higher consumption of feed although the feed conversion rate did not show significant differences between groups $(P>0.05)$.

Wang et al. (2008) observed a raised ADG with the inclusion of humic substances at $5 \%$ and $10 \%$ in the diets of the pigs. Trckova et al. (2018) also demonstrated the positive effect of leonardite (supplementation levels of $20 \mathrm{~g} / \mathrm{kg}$ in the diet) on BW, ADFI and ADG parameters of weaned piglets.

Although it is still not clearly exactly how leonardite exerts its action, the improvements in zootechnical performance seem to be related to the capacity of humic substances to help ion transport through membranes, the protection of intestinal mucosa, the enhancement of enzymes activities, and the better nutrient digestion and adsorption (particularly proteins and minerals) (Trckova 
Table 4

Zootechnical performance of in vivo trial (from day 0 to 40 ) divided by control (CTRL) and treatment (HAG supplemented with $0.25 \%$ of leonardite) group.

\begin{tabular}{|c|c|c|c|c|c|c|}
\hline & \multirow[b]{2}{*}{ CTRL } & \multirow[b]{2}{*}{ HAG } & \multirow[b]{2}{*}{ SEM \pm} & \multicolumn{3}{|l|}{$P$-values } \\
\hline & & & & Trt & Day & Trt $\times$ Day \\
\hline BW, kg & & & & 0.112 & $<0.001$ & $<0.001$ \\
\hline d 0 & 8.71 & 8.72 & 0.871 & & & \\
\hline d 14 & 11.11 & 12.21 & & & & \\
\hline d 28 & 15.44 & 18.36 & & & & \\
\hline d 40 & $20.17^{\mathrm{a}}$ & $24.25^{\mathrm{b}}$ & & & & \\
\hline ADFI, $\mathrm{kg} / \mathrm{d}$ & & & & 0.003 & $<0.001$ & 0.254 \\
\hline d $0-14$ & 0.353 & 0.465 & 0.034 & & & \\
\hline d $14-28$ & $0.651^{\mathrm{a}}$ & $0.841^{\mathrm{b}}$ & & & & \\
\hline d $28-40$ & $0.730^{\mathrm{a}}$ & $0.891^{\mathrm{b}}$ & & & & \\
\hline $\mathrm{ADG}, \mathrm{kg} / \mathrm{d}$ & & & & $<0.001$ & $<0.001$ & 0.535 \\
\hline d $0-14$ & 0.171 & 0.249 & 0.024 & & & \\
\hline d $14-28$ & $0.310^{\mathrm{a}}$ & $0.440^{\mathrm{b}}$ & & & & \\
\hline d $28-40$ & $0.396^{\mathrm{a}}$ & $0.491^{\mathrm{b}}$ & & & & \\
\hline \multicolumn{7}{|l|}{ FCR, $\mathrm{kg} / \mathrm{kg}$} \\
\hline d $0-14$ & 1,97 & 1,77 & 0,115 & 0.384 & 0.146 & 0.445 \\
\hline d $14-28$ & 1,93 & 1,79 & & & & \\
\hline d $28-40$ & 2,03 & 2,09 & & & & \\
\hline
\end{tabular}

a-b means with different superscripts are significantly different between treatments $(P<0.05)$.

Data are expressed as least squares means (LSMEANS) and standard error of the mean (SEM).

BW: body weight; ADG: average daily gain; ADFI: average daily feed intake; FRC: feed conversion rate; CTRL: control group; HAG: humic acid enriched diet group supplemented with $0.25 \%$ of leonardite.

et al., 2018).

Bai et al. (2013) estimated that the optimum level for increasing zootechnical performance was a $0.25 \%$ supplementation of fulvic acid. Therefore, a low concentration of HA inclusion may improve the growth performance with no influence on the diet composition and feed preparation.

Regarding the health status of the animals throughout the experimental period, only one piglet died at $\mathrm{d} 7$ in the CTRL group. This amounts to a mortality incidence of $<1 \%$, which could be considered as normal in common livestock farming. In both groups, clinical signs of diarrhoea occurred from d 14 to 21 and was transient (on average lasting three days). The occurrence of diarrhoea (number of new animals with fecal score $>1$ /total animals per group) was $18.6 \%$ and $16.7 \%$ in the CTRL and HAG groups at d 14, respectively. The occurrence of diarrhoea was below the average post weaning levels (Carstensen et al., 2005; Laine et al., 2008).

Our results confirmed the increase in BW, ADFI and ADG with a leonardite inclusion of $0.25 \%$, demonstrating that a lower inclusion level could equally enhance the zootechnical performance thus also optimizing the use of leonardite as a feed additive.

\subsection{Biological sample analysis}

The results of the serum metabolic parameters showed that the HAG group had higher levels of total proteins, albumin, A/G ratio, phosphatase alkaline, glucose, cholesterol, calcium, phosphorous, magnesium, high density lipoprotein, creatinine and total triglycerides $(P<0.05$, Table 5$)$.

All values were in the physiological range confirming that leonardite did not negatively affect the health status and should be considered as a safe feed additive. An increased albumin and total protein content are related to the age of piglets and their rapid growth (de Meer et al., 2000). The increased A/G ratio was a consequence of the higher albumin value, however no significant difference was observed for the globulin content, whose increase is often related to an inflammatory process (Bertoni et al., 2008).

The ALP content in serum showed a significant difference between the CTRL and HAG $(P<0.05)$ groups. ALP is an important marker of bone remodelling which is involved in cartilage maturation and calcification. ALP in serum is mainly synthetized by liver and bones, and is involved in the formation of phosphorous ions, whose combination with calcium leads to the formation of bone salts (Yuan et al., 2011). The increased ALP level in the HAG group could be explained by a growth burst of the piglets, also connected with a higher level of calcium and phosphorous in serum $(P<0.05)$.

The higher amount of serum magnesium $(P<0.05)$ in the HAG group suggests an enhanced response to stressors. Mg plays a crucial role as an enzymatic cofactor. When the animal is subjected to high levels of stress, catecholamines and stress-associated hormones are released leading to a shift in $\mathrm{Mg}$ from the intracellular to the extracellular space. This mechanism increases the urinary excretion of magnesium and subsequent decreases in the serum $\mathrm{Mg}$ concentrations. Thus, low serum Mg concentrations increase the release of stress-related hormones, thus establishing a feedback mechanism (Pouteau et al., 2018). Trckova et al. (2018) observed an increased amount of serum $\mathrm{Mg}$, Ca and $\mathrm{P}$ in weaned piglets supplemented with leonardite $(20 \mathrm{~g} / \mathrm{kg}$ of diet), thus confirming our findings and suggesting that humic substances could influence the mineral content of serum.

Although the fatty acid profile of the experimental diet was not affected by the inclusion of leonardite, the HAG group exhibited an increased concentration of total cholesterol and decreased triglycerides levels compared with the CTRL group ( $P<0.05$ ). The 
Table 5

Metabolic profile analysis of blood serum divided by control (CTRL) and treatment group (HAG supplemented with 0.25\% of HA) measured at day 40 .

\begin{tabular}{|c|c|c|c|c|}
\hline Analyte & CTRL & HAG & SEM \pm & P-Value \\
\hline Total protein content, g/L & $52.88^{\mathrm{a}}$ & $61.45^{\mathrm{b}}$ & 1.33 & $<0.001$ \\
\hline Albumin, g/L & $19.31^{\mathrm{a}}$ & $26.90^{\mathrm{b}}$ & 1.25 & $<0.001$ \\
\hline Globulin, g/L & 33.58 & 34.57 & 1.10 & 0.535 \\
\hline Albumin/globulin (A/G) & $0.58^{\mathrm{a}}$ & $0.81^{\mathrm{b}}$ & 0.05 & 0.002 \\
\hline Urea, mmol/L & 2.18 & 2.30 & 0.32 & 0.799 \\
\hline Alanine aminotransferase (ALT-GPT), IU/L & 38.33 & 47.80 & 3.79 & 0.093 \\
\hline Aspartate aminotransferase (AST-GOT), IU/L & 54.17 & 50.10 & 3.32 & 0.397 \\
\hline Phosphatase alkaline (ALP), IU/L & $165.67^{\mathrm{a}}$ & $228.50^{\mathrm{b}}$ & 14.41 & 0.006 \\
\hline Total bilirubin, $\mu \mathrm{mol} / \mathrm{L}$ & 1.98 & 2.40 & 0.24 & 0.238 \\
\hline Glucose, mmol/L & 5.00 & 5.94 & 0.35 & 0.075 \\
\hline Calcium, mmol/L & $2.28^{\mathrm{a}}$ & $2.65^{\mathrm{b}}$ & 0.06 & $<0.001$ \\
\hline Phosphorus, mmol/L & $3.05^{\mathrm{a}}$ & $3.73^{\mathrm{b}}$ & 0.09 & $<0.001$ \\
\hline Magnesium, mmol/L & $0.85^{\mathrm{a}}$ & $0.97^{\mathrm{b}}$ & 0.03 & 0.014 \\
\hline Creatinine, $\mu \mathrm{mol} / \mathrm{L}$ & 78.92 & 90.80 & 4.43 & 0.073 \\
\hline Total cholesterol, mmol/L & $2.51^{\mathrm{a}}$ & $2.92^{\mathrm{b}}$ & 0.12 & 0.024 \\
\hline High density lipoprotein (HDL), mmol/L & $0.77^{\mathrm{a}}$ & $1.00^{\mathrm{b}}$ & 0.03 & $<0.001$ \\
\hline Low density lipoprotein (LDL), mmol/L & 1.60 & 1.82 & 0.09 & 0.099 \\
\hline Triglycerides, mmol/L & $0.68^{\mathrm{a}}$ & $0.51^{\mathrm{b}}$ & 0.05 & 0.027 \\
\hline
\end{tabular}

a-b means with different superscripts are significantly different between treatments $(P<0.05)$.

Data are expressed as least squares means (LSMEANS) and standard error of the mean (SEM).

CTRL: control group; HAG: humic acid enriched diet group supplemented with 0.25\% leonardite.

increased cholesterol levels could be related to an increased HDL $(P>0.05)$ without any changes in the LDL amount. The increase in HDL may be related to an increased Mg concentration, whose presence or absence is strictly related to the incidence of cardiovascular and metabolic diseases (Verma and Garg, 2017). These results may also be due to the presence of phenolic compounds in leonardite which are recognized by EFSA as important nutrients in protecting blood lipids from oxidative damage and the maintenance of normal blood HDL-cholesterol concentrations without increasing LDL (EFSA, 2011, 2012).

In fact, total cholesterol concentration is an index of the lipometabolic status which includes the free and bounded forms of HDL (Wang et al., 2011). HDL protects blood vessels by decreasing cholesterol levels in the blood stream and guaranteeing their stabilization (Grela and Klebaniuk, 2007). These results suggest that leonardite has a positive effect on the lipidic metabolism as well as protecting blood vessels.

Results from the serum DAO analysis did not show any significant differences between the CTRL $(289.40 \pm 48.30 \mathrm{ng} / \mathrm{mL}) \mathrm{and}$ HAG $(263.13 \pm 33.95 \mathrm{ng} / \mathrm{mL})$ groups. The intact intestinal barrier plays a central role in preventing systemic infection and in the maintenance of the health status. DAO is abundantly expressed in the duodenal and jejunal mucosa and, therefore, DAO activity is a non-invasive marker of alterations in intestinal mucosal function and structure. Our results are in line with Liu et al. (2016) who showed an improvement in the gut barrier function, decreasing enteric diseases even without significant changes in serum DAO. An increased DAO level is often related to damage of the gut epithelium which releases this enzyme into the blood stream. Thus, the presence of DAO in healthy animals is usually scarce (Hou et al., 2014). Considering no occurrence of diarrhoea during the biological sample collection, although not representing the only indicator of a gut's barrier function, the detected levels of DAO did not reveal any intestinal alteration in either of the experimental groups.

Our RT-PCR data on fecal samples showed a significant reduction in bifidobacteria and lactobacilli in the HAG compared to the CTRL groups. Regarding E. coli and Enterobacteriaceae, no difference in abundance was observed.

Based on these preliminary data, it seems that leonardite particularly affects some groups of bacteria. Diarrhoea in piglets is often associated with specific pathogens, however the alteration in the gut microbiota composition can also be involved. In fact, Yang et al. (2017) analyzed the gut microbiota of diarrheic neonatal piglets in which no pathogenic E. coli were detected. The authors found an increase in Prevotella spp. and a reduction in E. coli and some beneficial bacteria belonging to the Firmicutes phylum. This altered microbiota led to diarrhoea in neonatal piglets. Yang et al. (2017) results indicate that changes in terms of the relationship between different groups of bacteria can provoke the development of piglet diarrhoea. These microbiota modifications cause the onset of the inflammatory state as well as different nutrient degradation and adsorption abilities. Further analyses are required to investigate the ability of leonardite to modulate the composition of gut microbiota in order to understand the mechanisms of its beneficial effects on piglet performance that we found in our study (Fig. 2).

\section{Conclusions}

Dietary supplementation with $0.25 \%$ leonardite improved the zootechnical performance, serum lipidic profile and gut epithelium integrity, thus indicating a good general health status. The increased serum HDL and decreased total triglycerides suggest that leonardite is a promising feed additive to improve lipid metabolism. The higher serum $\mathrm{Mg}$ content found also suggests that leonardite supports an improved stress response in weaned piglets. 

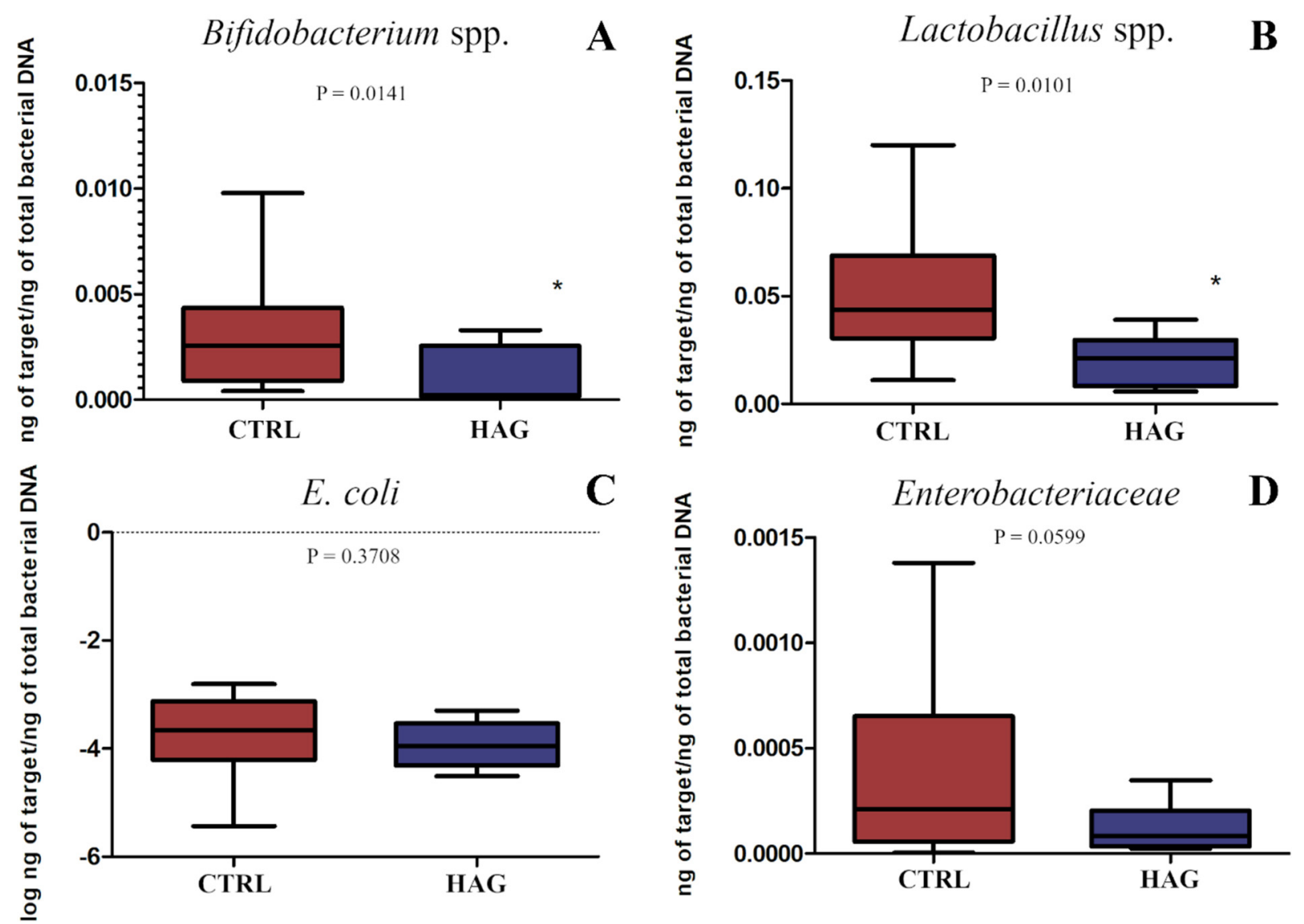

Fig. 2. Target DNA of principal microbial indicators of gut microbiota (A: Bifidobacterium spp., B: Lactobacillus spp., C: Escherichia coli, D: Enterobacteriaceae) on total bacterial DNA analyzed with RT-PCR divided by control and LEO group supplemented with $0.25 \%$ leonardite. *Means statistical differences between groups $(P<0.05)$.

CTRL: control group; HAG: humic acid enriched diet group supplemented with $0.25 \%$ leonardite.

Funding

This research was supported by the regional government of Lombardy and the European Regional Development Fund (ERDF) under grant: Foodtech Project (ID 203370).

\section{CRediT authorship contribution statement}

Matteo Dell'Anno: Writing - original draft, Writing - review \& editing, Investigation, Resources, Formal analysis, Data curation, Visualization. Monika Hejna: Writing - review \& editing, Investigation, Resources. Stefania Sotira: Writing - review \& editing, Investigation, Resources. Valentina Caprarulo: Formal analysis, Data curation, Writing - review \& editing, Investigation. Serena Reggi: Validation, Resources. Roberto Pilu: Formal analysis. Francesco Miragoli: Investigation. Maria Luisa Callegari: Investigation, Resources, Formal analysis. Sara Panseri: Formal analysis. Luciana Rossi: Supervision, Funding acquisition, Project administration, Writing - review \& editing.

\section{Declaration of Competing Interest}

The authors declare that they have no known competing financial interests or personal relationships that could have appeared to influence the work reported in this paper.

\section{Acknowledgments}

We are grateful to ProPhos Chemicals S.r.l. for project coordination and Ferraroni S.p.a. for providing the feed. Thanks are also due to Dr. Giancarlo Selmini who contributed to the in vivo trial diet formulation. 


\section{References}

Aeschbacher, M., Graf, C., Schwarzenbach, R., Sander, M., 2012. Antioxidant properties of humic substances. Environ. Sci. Technol. 46, $4916-4925$.

Aksu, T., Bozkurt, A., 2009. Effect of dietary essential oils and/or humic acids on broiler performance, microbial population of intestinal content and antibody titres in the summer season. Kafkas Universitesi Veteriner Fakultesi Dergisi 15, 185-190.

AOAC, 2005. Official Methods of Analysis, Washington, DC.

Attard, E., 2013. A rapid microtitre plate folin-ciocalteu method for the assessment of polyphenols. Cent. Eur. J. Biol. 8, 48-53.

Bai, H.X., Chang, Q.F., Shi, B.M., Shan, A.S., 2013. Effects of fulvic acid on growth performance and meat quality in growing-finishing pigs. Livest, Sci. 158 (1-3), 118-123.

Bartosch, S., Fite, A., Macfarlane, G.T., McMurdo, M.E., 2004. Characterization of bacterial communities in feces from healthy elderly volunteers and hospitalized elderly patients by using real-time PCR and effects of antibiotic treatment on the fecal microbiota. Appl. Environ. Microbiol. 70, 3575-3581.

Bertoni, G., Trevisi, E., Han, X., Bionaz, M., 2008. Effects of inflammatory conditions on liver activity in puerperium period and consequences for performance in dairy cows. J. Dairy Sci. 91, 3300-3310.

Byun, R., Nadkarni, M.A., Chhour, K.L., Martin, F.E., Jacques, N.A., Hunter, N., 2004. Quantitative analysis of diverse lactobacillus species present in advanced dental caries. J. Clin. Microbiol. 42, 3128-3136.

Carstensen, L., Ersbøll, A.K., Jensen, K.H., Nielsen, J.P., 2005. Escherichia coli post-weaning diarrhoea occurrence in piglets with monitored exposure to creep feed. Vet. Microbiol. 110 (1-2), 113-123.

Castrica, M., Rebucci, R., Giromini, C., Tretola, M., Cattaneo, D., Baldi, A., 2019. Total phenolic content and antioxidant capacity of agri-food waste and by-products. Italian J. Anim. Sci. 18, 336-341.

Chammui, Y., Sooksamiti, P., Naksata, W., Thiansem, S., Arqueropanyo, O., 2014. Removal of arsenic from aqueous solution by adsorption on leonardite. Chem. Eng. J. 240, 202-210.

Christie, W.W., Han, X., 2003. Lipid Analysis: Isolation, Separation, Identification and Structural Analysis of Lipids, third edition. The Oily Press, Bridgwater, England.

Commission Directive 2010/6/EU, 2010. Amending Annex I to Directive 2002/32/EC of the European Parliament and of the Council as Regards Mercury, Free Gossypol, Nitrites and Mowrah, Bassia, Madhuca (Text With EEA Relevance).

Commission Regulation E.U. 1275/2013, 2013. of 6 December 2013 Amending Annex I to Directive 2002/32/EC of the European Parliament and of the Council as Regards Maximum Levels for Arsenic, Cadmium, Lead, Nitrites, Volatile Mustard Oil and Harmful Botanical Impurities (Text With EEA Relevance).

Commission Regulation E.U. 2017/1017, 2017. Catalogue of Feed Materials (Text With EEA Relevance.).

Cormican, M., Hopkins, S., Jarlier, V., Reilly, J., Simonsen, G., Strauss, R., et al., 2017. ECDC, EFSA and EMA joint scientific opinion on a list of outcome indicators as regards surveillance of antimicrobial resistance and antimicrobial consumption in humans and food-producing animals. EFSA J. 15.

de Meer, K., Smolders, H., Meesterburrie, J., de Sain-van der Velden, M., Voorbij, H., Okken, A., Reijngoud, D., Kulik, W., 2000. A single food bolus stimulates albumin synthesis in growing piglets. J. Pediatr. Gastroenterol. Nutr. 31, 251-257.

Dell'Anno, M., Sotira, S., Rebucci, R., Reggi, S., Castiglioni, B., Rossi, L., 2020. In vitro evaluation of antimicrobial and antioxidant activities of algal extracts. Ital. J. Anim. Sci. 19 (1), 103-113.

Domínguez-Negrete, A., Gómez-Rosales, S., Angeles, M.D.L., López-Hernández, L.H., Reis-de Souza, T.C., López-García, Y., Zavala-Franco, A., Téllez-Isaias, G., 2019. Effect of the addition of humic substances as growth promoter in broiler chickens under Two feeding regimens. Animals 9 (12), $1-15$ 1101.

Efimova, I., Khil'ko, S., Smirnova, O., 2012. Antioxidant activity of humic acids in radical-Chain oxidation processes. Russ. J. Appl. Chem. 85, $1351-1354$.

EFSA Panel on Dietetic Products, Nutrition and Allergies (NDA), 2011. Scientific Opinion on the Substantiation of Health Claims Related to Polyphenols in Olive and Protection of LDL Particles from Oxidative Damage (ID 1333, 1638, 1639, 1696, 2865), Maintenance of Normal Blood HDL Cholesterol Concentrations (ID 1639), Maintenance of Normal Blood Pressure (ID 3781), “anti-inflammatory Properties”(ID 1882), "contributes to the Upper Respiratory Tract Health”(ID 3468), “can Help to Maintain a Normal Function of Gastrointestinal Tract”(3779), and "contributes to Body Defences Against External Agents" (ID 3467) Pursuant to Article 13(1) of Regulation (EC) No 1924/2006. EFSA J. 9 (4), 2033.

EFSA Panel on Dietetic Products, Nutrition and Allergies (NDA), 2012. Scientific opinion on the substantiation of a health claim related to polyphenols in olive and maintenance of normal blood HDL cholesterol concentrations (ID 1639, further assessment) pursuant to article 13 (1) of regulation (EC) No 1924/2006. EFSA J. 10 (8), 2848.

EGTOP/1/2011, 2011. Expert group for technical advice on organic production. Final Report on Feed.

Grela, E.R., Klebaniuk, R., 2007. Chemical composition of garlic preparation and its utilization in piglet diets. Med. Weter. 63, $792-795$.

Hejna, M., Moscatelli, A., Onelli, E., Baldi, A., Pilu, S., Rossi, L., 2019. Evaluation of concentration of heavy metals in animal rearing system. Ital. J. Anim. Sci. 18, $1372-1384$.

Heo, J.M., Opapeju, F.O., Pluske, J.R., Kim, J.C., Hampson, D.J., Nyachoti, C.M., 2013. Gastrointestinal health and function in weaned pigs: a review of feeding strategies to control post-weaning diarrhoea without using in-feed antimicrobial compounds. Anim. Physiol. Anim. Nutr. 2, $207-237$.

Hou, Y., Wang, L., Yi, D., Ding, B., Chen, X., Wang, Q., Zhu, H., Liu, Y., Yin, Y., Gong, J., Wu, G., 2014. Dietary supplementation with tributyrin alleviates intestinal injury in piglets challenged with intrarectal administration of acetic acid. Br. J. Nutr. 111, 1748-1758.

Islam, K.M.S., Schuhmacher, A., Gropp, J.M., 2005. Humic acid substances in animal agriculture. Pak. J. Nutr. 4, $126-134$.

Jessica, P., Amadou, D., Louis-Charles, R., Simon, B., 2019. Bioextracting polyphenols from the Brown seaweed ascophyllum nodosum from québec's North shore coastline. Ind. Biotechnol. 15, 212-218.

Ji, F., McGlone, J., Kim, S., 2006. Effects of dietary humic substances on pig growth performance, carcass characteristics, and ammonia emission. J. Anim. Sci. 84, $2482-2490$.

Kaevska, M., Lorencova, A., Videnska, P., Sedlar, K., Provaznik, I., Trckova, M., 2016. Effect of sodium humate and zinc oxide used in prophylaxis of post-weaning diarrhoea on faecal microbiota composition in weaned piglets. Veterinarni Medicina 61, 328-336.

Karadirek, Ş., Kanmaz, N., Balta, Z., Demirçivi, P., Üzer, A., Hızal, J., Apak, R., 2016. Determination of total antioxidant capacity of humic acids using CUPRAC, Folin-Ciocalteu, noble metal nanoparticle- and solid-liquid extraction-based methods. Talanta 153, 120-129.

Kaur, C., Kapoor, H.C., 2002. Anti-oxidant activity and total phenolic content of some Asian vegetables. Int. J. Food Sci. Tech. 37 (2), $153-161$.

Khil'ko, S., Efimova, I., Smirnova, O., 2011. Antioxidant properties of humic acids from brown coal. Solid Fuel Chem. 45, 367-371.

Kim, K., Bae, I., Cho, J., Choi, Y., Ha, J., Choi, J., 2019. Effects of humic acid and blueberry leaf powder supplementation in feeds on the productivity, blood and meat quality of finishing pigs. Food Sci. Anim. Resour. 39, 276-285.

Laine, T.M., Lyytikäinen, T., Yliaho, M., Anttila, M., 2008. Risk factors for post-weaning diarrhoea on piglet producing farms in Finland. Acta Vet. Scand. 50 (21), 1-11.

Liu, G., Guan, G., Fang, J., Martinez, Y., Chen, S., Bin, P., Duraipandiyan, V., Gong, T., Tossou, M., Al-Dhabi, N., Yin, Y., 2016. Macleaya cordata extract decreased diarrhea score and enhanced intestinal barrier function in growing piglets. Biomed Res. Int. 1-7.

Lv, J., Han, R., Huang, Z., Luo, L., Cao, D., Zhang, S., 2018. Relationship between molecular components and reducing capacities of humic substances. ACS Earth Space Chem. 2, 330-339.

Ma, G., Chen, Y., 2020. Polyphenol supplementation benefits human health via gut microbiota: a systematic review via meta-analysis. J. Funct. Foods 66 (103829), $1-11$.

Mennen, L.I., Walker, R., Bennetau-Pelissero, C., Scalbert, A., 2005. Risks and safety of polyphenol consumption. Am. J. Clin. Nutr. 81 (1), 326S-329S.

Nilsson, J., Pillai, D., Önning, G., Persson, C., Nilsson, ̊., Akesson, B., 2005. Comparison of the 2, 2'-azinobis-3-ethylbenzotiazo-line-6-sulfonic acid (ABTS) and ferric reducing anti-oxidant power (FRAP) methods to asses the total antioxidant capacity in extracts of fruit and vegetables. Mol. Nutr. Food Res. 49 (3), 239-246.

NRC, 2012. Nutrient Requirements of Swine. National Research Council. The National Academies Press, Washington, DC.

Ozturk, E., Ocak, N., Turan, A., Erener, G., Altop, A., Cankaya, S., 2012. Performance, carcass, gastrointestinal tract and meat quality traits, and selected blood parameters of broilers fed diets supplemented with humic substances. J. Sci. Food Agric. 92 (1), 59-65.

Patrone, V., Minuti, A., Lizier, M., Miragoli, F., Lucchini, F., Trevisi, E., Rossi, F., Callegari, M.L., 2018. Differential effects of coconut versus soy oil on gut microbiota 
composition and predicted metabolic function in adult mice. BMC Genom. 19 (1), 1-17 808.

Penders, J., Vink, C., Driessen, C., London, N., Thijs, C., Stobberingh, E.E., 2005. Quantification of bifidobacterium spp., Escherichia coli and clostridium difficile in faecal samples of breast-fed and formula-fed infants by real-time PCR. FEMS Microbiol. Lett. 243, 141-147.

Pouteau, E., Kabir-Ahmadi, M., Noah, L., Mazur, A., Dye, L., Hellhammer, J., Pickering, G., Dubray, C., 2018. Superiority of magnesium and vitamin B6 over magnesium alone on severe stress in healthy adults with low magnesemia: a randomized, single-blind clinical trial. Plos One 13 (12), 1-17.

Prior, R., Wu, X., Schaich, K., 2005. Standardized methods for the determination of antioxidant capacity and phenolics in foods and dietary supplements. J. Agric. Food. Chem. 53, 4290-4302.

Regulation E.C. 1831/2003, 2003. of the European Parliament and of the Council, of 22 September 2003 on Additives for Use in Animal Nutrition (Text With EEA Relevance).

Rossi, L., Vagni, S., Polidori, C., Alborali, G.L., Baldi, A., Dell'Orto, V., 2012. Experimental induction of Escherichia coli diarrhoea in weaned piglets. Open J. Vet. Med. $2,1-8$.

Rossi, L., Dell'Orto, V., Vagni, S., Sala, V., Reggi, S., Baldi, A., 2014. Protective effect of oral administration of transgenic tobacco seeds against verocytotoxic Escherichia coli strain in piglets. Vet. Res. Commun. 38, 39-49.

Smirnova, O., Efimova, I., Khil'ko, S., 2012. Antioxidant and pro-oxidant activity of ascorbic and humic acids in radical-Chain oxidation processes. Russ. J. Appl. Chem. $85,252-255$

Trckova, M., Lorencova, A., Hazova, K., Zajacova, Z., 2015. Prophylaxis of post-weaning diarrhoea in piglets by zinc oxide and sodium humate. Veterinarni Medicina $60,351-360$

Trckova, M., Lorencova, A., Babak, V., Neca, J., Ciganek, M., 2017. Effects of sodium humate and zinc oxide used in prophylaxis of post-weaning diarrhoea on the health, oxidative stress status and fatty acid profile in weaned piglets. Veterinární medicína 62 (1), 16-28.

Trckova, M., Lorencova, A., Babak, V., Neca, J., Ciganek, M., 2018. The effect of leonardite and lignite on the health of weaned piglets. Res. Vet. Sci. 119, 134-142.

Verma, H., Garg, R., 2017. Effect of magnesium supplementation on type 2 diabetes associated cardiovascular risk factors: a systematic review and meta-analysis. J. Hum. Nutr. Diet. 30 (5), 621-633.

Wang, Q., Chen, Y., Yoo, J., Kim, H., Cho, J., Kim, I., 2008. Effects of supplemental humic substances on growth performance, blood characteristics and meat quality in finishing pigs. Livest. Sci. 117, 270-274.

Wang, J., Wu, C., Feng, J., 2011. Effect of dietary antibacterial peptide and zinc-methionine on performance and serum biochemical parameters in piglets. Czech J. Anim. Sci. 56, 30-36.

Yang, Q., Huang, X., Zhao, S., Sun, W., Yan, Z., Wang, P., Li, S., Huang, W., Zhang, S., Liu, L., Gun, S., 2017. Structure and function of the fecal Microbiota in diarrheic neonatal piglets. Front Microbiol. 8 (502), 1-13.

Yuan, X., Wang, J., Zhu, X., Zhang, Z., Ai, Y., Sun, G., Wang, Z., Liu, G., 2011. Effect of copper on levels of collagen and alkaline phosphatase activity from chondrocytes in newborn piglets in vitro. Biol. Trace Elem. Res. 144, 597-605.

Zhang, J., Lv, Y., Tang, C., Wang, X., 2013. Effects of dietary supplementation with palygorskite on intestinal integrity in weaned piglets. Appl. Clay Sci. 86, 185-189.

Zhao, J., Harper, A.F., Estienne, M.J., Webb Jr., K.E., McElroy, A.P., Denbow, D.M., 2007. Growth performance and intestinal morphology responses in early weaned pigs to supplementation of antibiotic-free diets with an organic copper complex and spray-dried plasma protein in sanitary and nonsanitary environments. J. Anim. Sci. 85 (5), 1302-1310. 